\title{
Simulation and Parametric Analysis of Cryogenic Oxygen Plant for Biomass Gasification
}

\author{
Vaijanath N. Raibhole ${ }^{1} \&$ S. N. Sapali ${ }^{2}$ \\ ${ }^{1}$ MES's college of Engineering, Pune, India \\ ${ }^{2}$ College of Engineering, Pune, India \\ Correspondence: Vaijanath N. Raibhole, MES's College of Engineering, Late principal V. K. Joag Path, Wadia \\ college campus, Pune, India. Tel: 91-800-793-7370. E-mail: vraibhole@gmail.com
}

Received: September 18, $2012 \quad$ Accepted: October 18, $2012 \quad$ Online Published: November 6, 2012

doi:10.5539/mer.v2n2p97

URL: http://dx.doi.org/10.5539/mer.v2n2p97

\begin{abstract}
Cryogenic air separation plants are used for production of oxygen, nitrogen and argon with required purity and recovery.The first grade oxygen (purity over 99.99\%) is required for welding, cutting, and medical applications. These plants operate at low thermodynamic efficiency with specific power consumption in a range between 0.5-0.6 kw/scmh of $\mathrm{O}_{2}$. As air gasification produces poor quality syngas, oxygen is used as gasifying agent for biomass gasification. Medium purity cryogenic air separation units (ASU) are chiefly required for gasification. Biomass gasification with oxygen as gasifying agent has great potential in applications like integrated gasification combined cycle (IGCC), chemical production and Fischer-Tropsch (F-T) products. In this work simulation of medium purity oxygen cryogenic air separation plant integrated with biomass gasifier is carried out by using Aspen plus. Such cryogenic air separation plants which produce oxygen in a range between $85-98 \%$ can be used economically for gasification. The cryogenic oxygen plant produces oxygen with purity $96.2 \%$ mole basis with specific power consumption as $0.2435 \mathrm{kw} / \mathrm{scmh}$ of $\mathrm{O}_{2}$. The performance parameters like recovery, purity, temperature and pressure and power consumption of cryogenic air separation unit are obtained. The parameters like syngas composition and heating value also predicted in simulation of biomass gasifier. The effect of parameters (parametric analysis), like vapour fraction of the feed on pure liquid (PL) flow and condenser duty, effect of number of stages on PL and rich liquid (RL) flow and its purity and effect of oxygen flow and gasifier temperature on syngas composition is discussed.
\end{abstract}

Keywords: ASPEN plus, biomass gasification, cryogenic ASU, IGCC, parametric analysis, syngas

\section{Introduction}

The development of cryogenic ASU has been taken place through various stages. As the process cycle improvement is one of the areas for further development in cycle towards performance. So to understand thermodynamics of the process cycle simulation of various unit operations in a cryogenic ASU is essential. ASPEN plus (Advanced System for Process Engineering Plus) is one of the process simulator used for modeling cryogenic air separation plant and biomass gasification. It is a steady state chemical process simulator, which was developed at Massachusetts Institute of Technology (MIT) for the US DOE, to evaluate synthetic fuel technologies. It uses unit operation blocks, which are models of specific process operations (reactors, heaters, pumps etc.). The user places these blocks on a flow sheet, specifying material and energy streams.

Aspen plus is one of the most powerful and widely used process simulators in the process industry today. It has several features that make it very intuitive and user friendly. Its graphic user interface and model manager make an excellent guide for the user and allow for complete specifications and control at every stage of model development (Aspen Tech, User Manual, 2011). Many large scale applications like gasification demands second grade (medium purity) oxygen. The first grade oxygen production is too expensive which may not economical as oxygen costs in such applications are critical. There are different methods available for production of second grade oxygen as mentioned by (Schuftan, 1948) with merits and demerits. The continuous development of air separation cycles has been taking place in terms of recovery, power consumption, purity, cost of manufacturing, ease of maintenance etc. (Castle, 2000; Sapali, 2001; Agrawal et al., 1989; Zhu et al., 2006; Mandler, 2000; Smith et al., 2001; Zhu et al., 2010). Gasification involves the production of gaseous fuel mainly consisting of carbon monoxide $(\mathrm{CO})$, carbon dioxide $\left(\mathrm{CO}_{2}\right)$, hydrogen $\left(\mathrm{H}_{2}\right)$, and with traces of methane $\left(\mathrm{CH}_{4}\right)$; with useable 
heating value by partial combustion of solid fuel. Feedstocks of gasification like biomass and inferior quality coal have great potential for energy production. Currently energy is recovered from these fuels through combustion. The efficiency of these plants is very less. Thus coal/biomass gasification unit integrated with combined power cycle offers higher efficiencies up to $60 \%$ (Doherty et al., 2008). As one of the attempt to study performance of gasifier with air as gasifying agent, an equilibrium model based on minimization of Gibbs free energy was developed for rubber wood and syngas composition obtained by (Paviet et al., 2009). Where as mathematical model in Engineering Equation Solver (EES) was used to predict syngas composition in a small downdraft gasifier (Chawdhury et al., 2011). However thermodynamic equilibrium composition prediction is the important step in modeling the gasification process. An equilibrium model for biomass gasifier is developed and equilibrium relations are solved by using MATLAB to get syngas composition and its properties (Khadse et al., 2006). In addition exergy analysis performed on the basis of thermodynamic equilibrium for different feedstocks by (Shrinivas et al., 2009). Gasification of rice husk was tested in fluidized bed gasifier experimentally for studying various parameters like syngas composition, temperature and heating value of syngas obtained by (Mansaray et al., 2010). Such clean syngas obtained from a gasifier can be used as fuel for a large combined cycle system for electricity generation, where the gasified fuel is first burnt in a combustion turbine-generator unit, and then the hot exhaust gas from its gas turbine is used for generating steam to produce further power in a steam turbine-generator unit. The combination of a gasifier and a combined cycle is called the IGCC. Including IGCC, other different applications where syngas can be used are highlighted in (Chen et al., 2010). The multitude applications of syngas can be shown in Figure 1. In today's scenario biomass gasification with oxygen as gasifying agent has great potential.

The aim of the present work is to simulate medium purity oxygen cryogenic plant by using Aspen plus for gasification application and found out specific power consumption of cryogenic ASU. It is also an attempt to develop a model of biomass/coal gasifier with air/oxygen and steam as oxidizing agent by using Aspen plus. Simulation of biomass gasifier based on Gibbs free energy minimization is performed. The syngas is obtained with various parameters like syngas composition, temperature, heating value for different feedstocks as rice husk, wood pallets and Indian charcoal. The parametric analyses also discussed for cryogenic ASU and biomass gasifier.

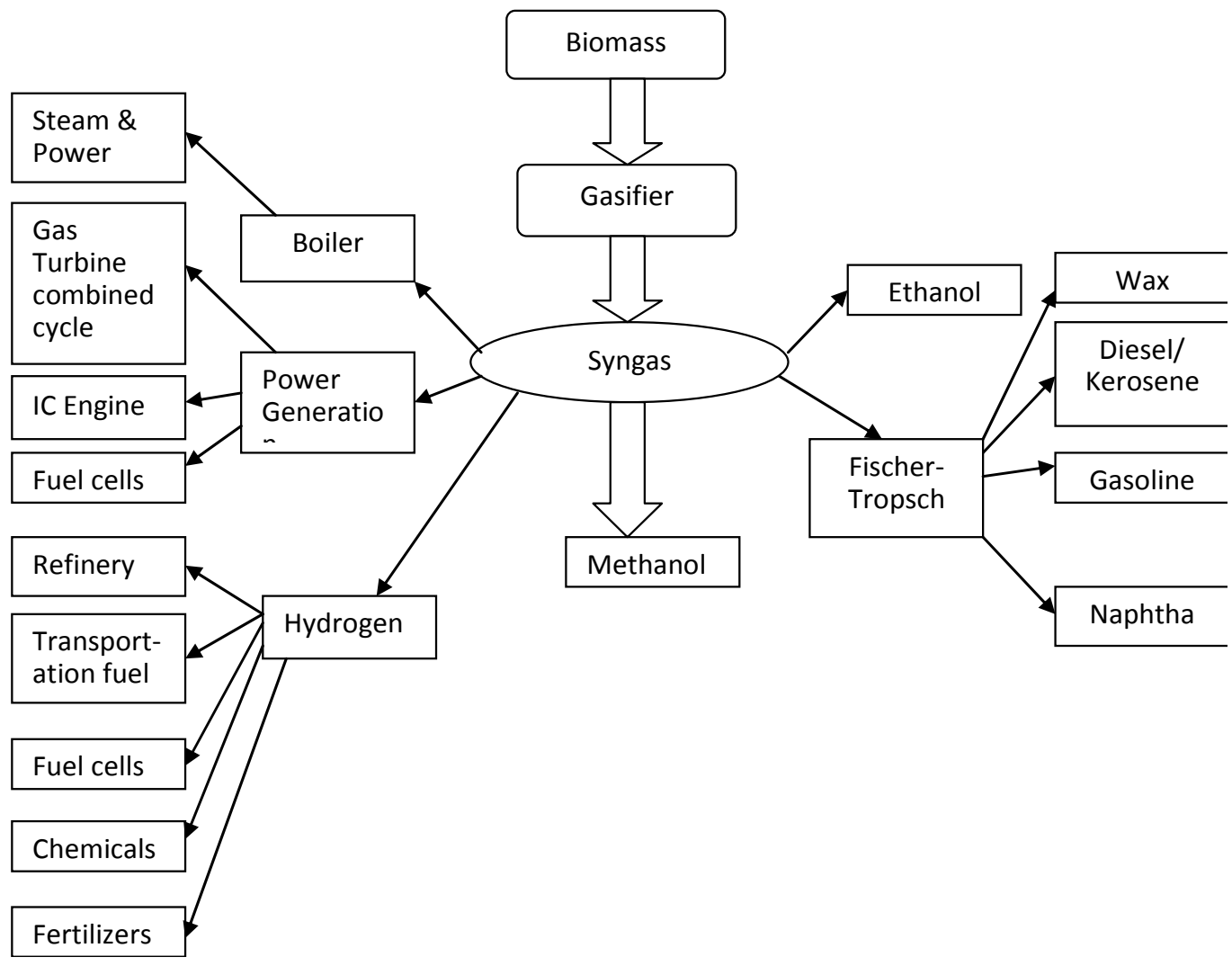

Figure 1. Multitude applications of syngas 


\section{Cryogenic Air Separation Modeling}

Distillation has long been used for air separation. The three major components of air (nitrogen, oxygen and argon), do not form any azeotropes and can be separated by simple distillation. Cooling is achieved through the Joule-Thomson effect, if higher pressure air gets expand; it cools down and can be partially liquefied. To simulate this process the Peng Robinson EOS is used. The cryogenic air separation process is a tight integration of heat exchangers and separation columns which is completely driven by the compression of the air at the inlet of the unit. The air inlet stream is cooled to ambient temperatures with cooling water which is further cooled against product and waste streams leaving the plant until partially liquefied. The liquefied fraction varies between 25 to $35 \mathrm{~mol} \%$ depending on cooling water temperature and compressor outlet pressure. This stream enters the bottom of a high pressure (HP) column that produces pure liquid nitrogen (impurities 1ppm) at the top of HP column. The HP column has roughly 40 equilibrium stages including condenser and operates at high pressure. The cooling medium in the condenser of HP column is the oxygen, bottom product produced in a second column. Thus, this second column must operate at a lower pressure to make the reboiler colder than the condenser of the HP column (typically by 1 Kelvin only). Thus, the pressures of both columns are linked mainly by the vapour pressures of nitrogen and oxygen and the temperature approach of the combined condenser/reboiler. In order to exit oxygen from the plant, the bottom of the low pressure (LP) column is typically around 1.2 bars which set a pressure of at least 5.7 bars for the HP column. Therefore compressor is required to deliver air at slightly higher pressure. These two columns share the same column shell to minimize the temperature difference between the condensing nitrogen and evaporating oxygen. The liquid bottom product of the HP column is rich in oxygen called rich liquid. When this rich liquid is reduced in pressure, the Joule-Thomson effect causes this rich liquid to cool further which is fed to the LP column. Additional refrigeration is obtained by compressing air in a second stage compressor to a high pressure and expands in expander. This air feeds directly to LP column through Joule -Thomson valve. Finally, the LP column is refluxed with liquid nitrogen from the HP column, after having been flashed and cooled by the Joule-Thomson effect. The liquid oxygen from the bottom of LP column is gasified and heated against the incoming air in the main heat exchanger. The pure gaseous nitrogen of the top of the LP column is also heated to atmospheric conditions against the incoming air. The products of the ASU are thus gaseous nitrogen $\left(\mathrm{GN}_{2}\right)$ and oxygen $\left(\mathrm{GO}_{2}\right)$.

\section{Gaseous Oxygen Plant}

There is large demand for the gaseous oxygen in the decarburization of steel, in an electric arc and open- hearth furnaces and also in the bottom-blown Bessemer process of steel production in the steel industry. The steel making process needs gaseous oxygen to accelerate the oxidation and conversion of iron to steel. The oxygen purity required for above mentioned application is $99.99 \%$ (mole $\%$ basis). Gasification is one of the applications which require huge quantity of medium pure gaseous oxygen with purity $94 \%$ to $96 \%$ (mole $\%$ basis). It is because air gasification produces a poor quality gas with regard to the heating value, around 4-9 $\mathrm{MJ} / \mathrm{Nm}^{3}$ higher heating value while $\mathrm{O}_{2}$ and steam blown processes result in a syngas with a heating value in the range of 10-20 $\mathrm{MJ} / \mathrm{Nm}^{3}$.

\subsection{Simulation of Cryogenic ASU for Gaseous Oxygen Production}

The cryogenic distillation of air is currently the only method available for the large oxygen production rates required for future fossil fuel gasification and oxy-fuel combustion with $\mathrm{CO}_{2}$ capture. The current large scale users are the chemical, steel and petroleum industries. $\mathrm{O}_{2}$ purities of up to $97 \%$ are economically favored for gasification application as this requires the much easier separation of $\mathrm{N}_{2}$ from $\mathrm{O}_{2}$. Production of $99.99 \% \mathrm{O}_{2}$ requires the more difficult $\mathrm{O}_{2} / \mathrm{Ar}$ separation with up to double the number of separation stages in a distillation column. A process flow diagram of cryogenic air separation system is shown in Figure 2. Separation of over $95 \%$ of the $\mathrm{O}_{2}$ in the air feed at $90 \%$ to $97 \%$ molar concentration is carried out in two distillation columns thermally linked by a dual-function heat exchanger called as reboiler/condenser. This heat exchanger serves as a reboiler for the HP column and as a condenser for LP column. The LP column operates at low pressure as 1.2 bars which are close to ambient pressure to minimize energy use. The HP column operates at pressure 4 bar.

\subsection{Simulation Considerations}

The simulation considerations for cryogenic air separation unit are given as below.

1. Air flow : $1000 \mathrm{scmh}$

2. Compressor discharge pressure : 4.2 bar

3. LP Pressure $: 1.2 \mathrm{bar}$

4. HP Pressure : 4 bar 
5. No. of stages in LP column : :56

6. No. of stages in HP column : : 40

7. Heat leak $: 15 \mathrm{kw}$

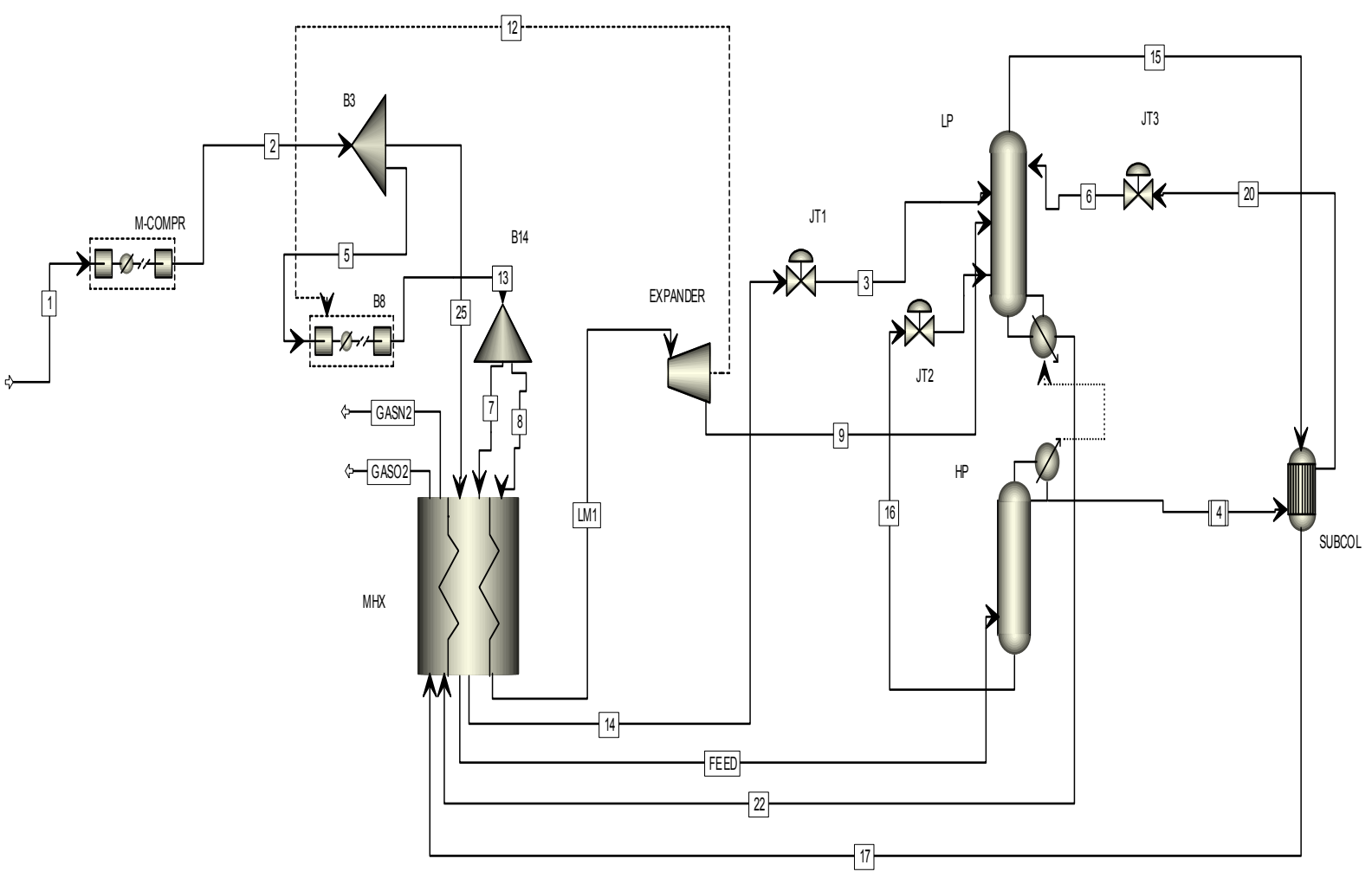

Figure 2. Process flow diagram of cryogenic gaseous oxygen plant

Filtered air is first compressed to 4.2 bars and cooled to $45^{\circ} \mathrm{C}$ temperature by water cooled heat exchanger. The compressed air then enters a main heat exchanger and is further cooled and partially liquefied by countercurrent heat exchanger with cold nitrogen and oxygen streams from the columns. Partially liquefied air at 4.2 bars pressure enters the HP column. The separated $\mathrm{N}_{2}$ gas condenses to provide reflux to the HP column and enters to the LP column after sub cooling in the sub-cooler. Up to $30 \%$ of the air is further compressed to a pressure of 50 bars which gives a positive temperature difference. The refrigeration balance on the plant is provided by expanding a portion of the high pressure air stream in a turbine. The discharge air stream from expander is feed to LP column. The $\mathrm{O}_{2}$ rich liquid stream and a high pressure fraction of the air which has been liquefied are the feed streams to the LP column. The distillation separates $\mathrm{N}_{2}$ gas stream from top of LP column and a liquid $\mathrm{O}_{2}$ stream from bottom of LP column are supplied to main heat exchanger and heated to ambient temperature, which cools and partially liquefies the air feed streams.

\section{Modeling of Biomass Gasifier}

Gasification is a process that involves many complex reactions that depend on chemical kinetics, reactor geometry, and many other parameters. As a result, the complexity of simulating gasification is simplified by modeling the process based on thermodynamic and chemical equilibrium. Equilibrium is a good assumption provided the residence time is long enough; however, in the case of most real world gasifiers this is not the case. A reacting system is at its most stable composition at chemical equilibrium. This state is achieved when the entropy of the system is maximized and its Gibbs free energy is minimized. Minimization of the Gibbs free energy of the products is the method used to calculate equilibrium in this work. Aspen plus provides a unit operation model called RGIBBS that calculates chemical and thermodynamic equilibrium based on minimizing the Gibbs free energy of the system. Components in Aspen plus are classified as either conventional or 
nonconventional. Conventional components are ones with property data contained in the Aspen plus component database. Nonconventional components are non-homogeneous substances that do not have a consistent composition and are not contained in the Aspen plus component database. These components, which would include coal and biomass, must be given physical attributes, such as those defined by the ultimate, proximate, and sulfur analyses. Property methods must also be chosen to calculate the enthalpy and density of the substance. For this work, the property methods HCOALGEN and DCOALIGT were respectively chosen to calculate the enthalpy and density of biomass. These property methods use statistical correlations to calculate the specific heat, enthalpy, and density of coal and coal-derived substances based on the ultimate, proximate, and sulfur analyses. Biomass can be represented as a technical fuel through these analyses, these property methods were also used for calculating the thermodynamic properties of biomass fuels. Furthermore, the property method HCOALGEN offers different options for how the enthalpy of formation of the component is calculated. For this work, the enthalpy of formation was calculated based on the higher heating value of the substance, which was specified through ultimate analysis of biomass. The equilibrium reactor RGIBBS does not accept nonconventional components as reactants. As a result, the fuel must be decomposed to conventional components which can be used by the RGIBBS block. The conversion is accomplished with an RYIELD block, labeled DECOMP, which is a reactor model that generates products based on known yields. The fuel feed stream enters DECOMP where it is decomposed into its elemental constituents. A FORTRAN calculator script interacts with the RYIELD block such that decomposition of the fuel is calculated based on the proximate and ultimate analyses of the nonconventional component. The carbon content of the feed is converted to solid carbon graphite. The hydrogen, oxygen, nitrogen, chlorine, and sulfur are converted to gaseous $\mathrm{H}_{2}, \mathrm{O}_{2}, \mathrm{~N}_{2}, \mathrm{Cl}_{2}$, and $\mathrm{S}$. Finally the moisture content is converted to liquid $\mathrm{H}_{2} \mathrm{O}$. These species are now contained in an intermediate stream called INGASFR, which then become the reactants for the RGIBBS block. An $\mathrm{O}_{2} /$ air and steam streams representing the gasifying oxidant also enters RGIBBS reactor, and a products stream exits it. The heat stream QDECOMP connect the DECOMP and RGIBBS reactor and represents the energy required to decompose the solid fuel. Although QDECOMP interacts with RGIBBS reactor, the reactor is still considered to be adiabatic because DECOMP calculates the amount of heat required for decomposition and draws it from RGIBS reactor.

\section{Simulation of Biomass Gasifier with Air/Oxygen as Gasifying Agent}

The simulation model of biomass gasification consists of two stages; biomass decomposition and gasification reaction with steam and oxygen. In decomposition stage, biomass is decomposed into its elements like $\mathrm{C}, \mathrm{H}, \mathrm{O}$, $\mathrm{S}, \mathrm{N}$ and $\mathrm{H}_{2} \mathrm{O}$. The Aspen plus yield reactor RYIELD is used to simulate decomposition of the feed. The stream biomass is specified as non-conventional stream and ultimate and proximate analyses are given as input along with thermodynamic conditions and mass flow rate. The Aspen plus Gibbs reactor, RGIBBS is used for partial combustion based on assumption that reactions of biomass elements with oxygen follow Gibbs equilibrium. The products from RGIBBS reactor are fed to separator block. The top outlet stream which is called SYNGAS is composed of all the gases. The Process flow diagram of biomass gasification with air/oxygen and steam is shown in Figure 3.

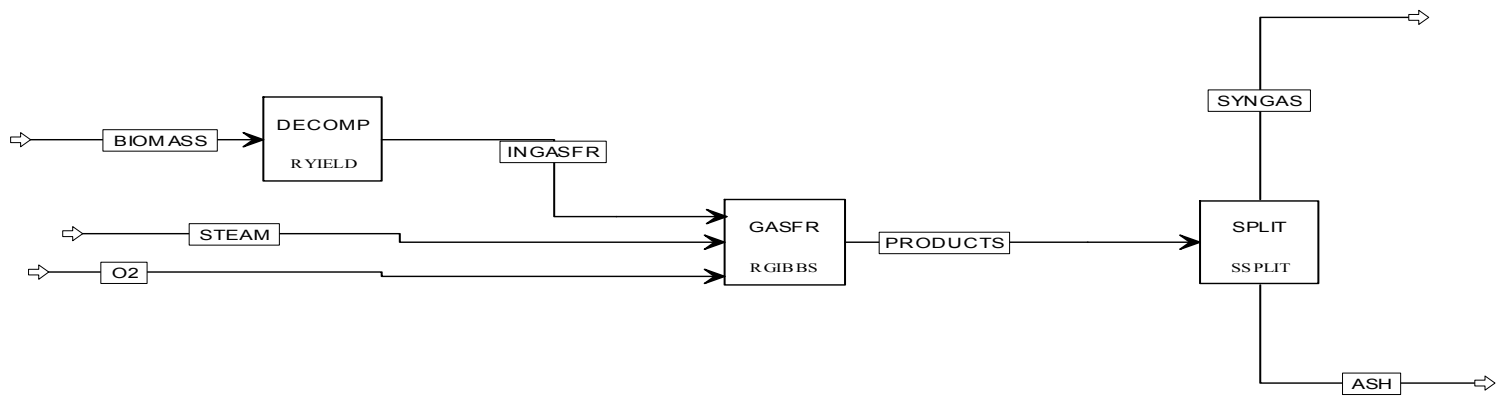

Figure 3. Process flow diagram of biomass gasification with air/oxygen as gasifying agent

\subsection{Characteristics of Feedstock's and Simulation Parameters of Model}

On the basis of process cycle design calculations, the main simulation parameters in cryogenic ASU integrated with gasifier model are: Oxygen flow rate- $10 \mathrm{~kg} / \mathrm{hr}$, Steam flow rate- $8 \mathrm{~kg} / \mathrm{hr}$, Input biomass mass flow-33.6 $\mathrm{kg} / \mathrm{hr}$ and gasification pressure-1.05 bar. The proximate and ultimate analyses of different feed stocks are given in Table 1. 
Table 1. Proximate and ultimate analyses of different feedstocks

\begin{tabular}{llllllllllll}
\hline Feedstock & \multicolumn{9}{c}{ Proximate Analysis $(\%$ mole $)$} & \multicolumn{7}{c}{ Ultimate Analysis (\% mole ) } & \\
\hline & FC & VM & Moisture & ASH & C & H & O & N & S & CL \\
\hline Indian coal & 39.83 & 26.74 & 5.9 & 27.53 & 56.09 & 3.58 & 6.05 & 0.72 & 0.24 & - \\
Rice Husk & 14.8 & 84.8 & 11.7 & 0.4 & 36.42 & 4.91 & 35.88 & 0.59 & -- & - \\
Wood pellets & 10 & 85 & 8.55 & 0.574 & 48 & 8 & 46 & -- & -- & - \\
\hline
\end{tabular}

\section{Results and Discussion}

In this simulation, it is found that a total of $209.78 \mathrm{scmh}$ of gaseous $\mathrm{O}_{2}$ product with $96.2 \%$ purity is produced which is safely used for gasification application. Gaseous $\mathrm{N}_{2}$ byproduct with purity $99.9 \%$ is also produced at volumetric flow rate of $734 \mathrm{scmh}$. Heat duties of the reboiler of the LP column and condenser of the HP column are matched by calculator block in Aspen plus. It is observed that from simulation results, the main compressor consumes $47.22 \mathrm{~kW}$ power and booster consumes $12.22 \mathrm{~kW}$ power, which is partially compensated by the power of $9.32 \mathrm{~kW}$ generated in the expander. The specific power consumption is obtained is $0.2435 \mathrm{kw} / \mathrm{scmh}$ of $\mathrm{O}_{2}$. The details simulation result of cryogenic ASU for oxygen production are shown in table 2.

Steady state simulation model of biomass gasifier in Aspen plus predicts the composition of syngas. Syngas composition for different biomass with air and oxygen as gasifying agent are shown in table.3. It is found that from table. 3, with oxygen as gasifying agent $\mathrm{H}_{2}$ and $\mathrm{CO}$ in syngas composition are increased as it is not diluted with nitrogen. Heating value of syngas with air as gasifying agent is low as compared with oxygen as gasifying agent. Syngas with low heating value is suitable for applications like boiler and engine applications where as syngas with medium or high heating value suitable for F-T Process.

Table 2. Simulation results of gaseous oxygen plant

\begin{tabular}{lcccc}
\hline Parameters & FEED & $\mathrm{GASN}_{2}$ & $\mathrm{GASO}_{2}$ & $\mathrm{LM} 1$ \\
\hline Temperature(K) & 95.5 & 300.1 & 302.8 & 283.1 \\
Pressure (bar) & 4.1 & 1.1 & 1.15 & 50 \\
Vapor Fraction & 0.9 & 1 & 1 & 1 \\
\hline Mass Fraction & & & & \\
\hline $\mathrm{N}_{2}$ & 0.755 & 0.998 & $5 \mathrm{ppb}$ & 0.755 \\
$\mathrm{O}_{2}$ & 0.232 & $18 \mathrm{ppm}$ & 0.953 & 0.232 \\
$\mathrm{Ar}$ & 0.013 & 0.002 & 0.047 & 0.013 \\
\hline $\mathrm{Mole}$ Flow (scmh) & & & & \\
\hline $\mathrm{N}_{2}$ & 663.765 & 780.900 & $\mathrm{TRACE}$ & 114.792 \\
$\mathrm{O}_{2}$ & 178.33 & 0.012 & 209.78 & 30.814 \\
$\mathrm{Ar}$ & 7.905 & 1.088 & 8.212 & 1.367 \\
\hline $\mathrm{Mole}$ Fraction & & & & \\
\hline $\mathrm{N}_{2}$ & 0.781 & 0.999 & $6 \mathrm{ppb}$ & 0.781 \\
$\mathrm{O}_{2}$ & 0.210 & $16 \mathrm{ppm}$ & 0.962 & 0.21 \\
$\mathrm{Ar}$ & 0.009 & 0.001 & 0.038 & 0.009 \\
\hline
\end{tabular}


Table 3. Syngas composition of different feedstocks

\begin{tabular}{ccccccccc}
\hline \multirow{2}{*}{ Feedstock } & $\begin{array}{c}\text { Gasifying } \\
\text { Agent }\end{array}$ & \multicolumn{7}{c}{ Syngas composition( \% mole) } \\
\hline \multirow{2}{*}{ Indian coal } & & $\mathrm{H}_{2}$ & $\mathrm{CO}$ & $\mathrm{CO}_{2}$ & $\mathrm{H}_{2} \mathrm{O}$ & $\mathrm{CH}_{4}$ & $\mathrm{~N}_{2}$ & $\mathrm{CV}(\mathrm{MJ} / \mathrm{kg})$ \\
\cline { 2 - 9 } & Air & 8.8 & 41.8 & 0.623 & 0.018 & 17.3 & 32 & 12.59 \\
\hline \multirow{2}{*}{ Rice Husk } & Oxygen & 15.3 & 60.1 & 0.003 & 0.492 & 0.23 & 0.8 & 19.55 \\
\cline { 2 - 9 } & Air & 22.9 & 18.4 & 13.0 & 8.3 & 0.8 & 36.6 & 5.49 \\
\hline \multirow{2}{*}{$\begin{array}{l}\text { Wood } \\
\text { pellets }\end{array}$} & Oir & 32.1 & 29.8 & 7.9 & 5.7 & 0.9 & 23.6 & 9.22 \\
\cline { 2 - 9 } & Oxygen & 4.07 & 37.8 & 11.3 & 8.1 & 1.7 & 0.9 & 13.19 \\
\hline
\end{tabular}

\section{Sensitivity Analysis for Cryogenic ASU Integrated with Biomass Gasifier}

The sensitivity analysis tool is used in this study to analyze and predict the behavior of the model to changes in key operating and design variables. In this sensitivity analyisis, process variables like vapour fraction (VF), temperature, oxygen flow and number stages etc. on desired output are studied. These studies are helpful in predicting scenarios over a range of operating variables and provide solutions in a "What-If" analysis.

\subsection{Effect of VF on Pure Liquid (PL) Flow (Distillate of HP Column)}

As VF of feed increases, the quantity of vapour entering the column gets increased and consequently the net vapour reaching the top stage increased. Therefore, at higher VF of the feed air and for constant purity of top product, the PL flow out of the column increases as shown in Figure 4.

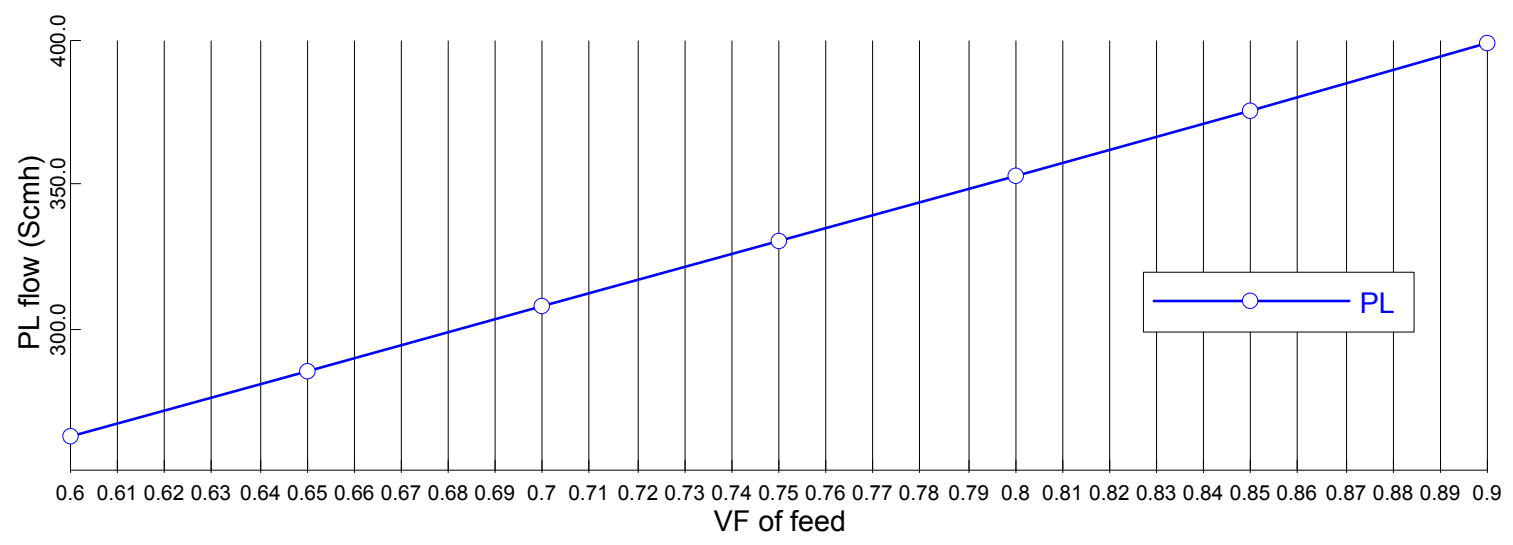

Figure 4. Effect of VF on PL flow

\subsection{Effect of VF on Condenser Duty of HP Column}

As VF of feed increases, the quantity of vapour at the top of distillation column will be more. These vapours are condensed by condenser provided at the top of the distillation column. As a result, condenser duty increases with increase in VF of the feed as shown in Figure 5. 


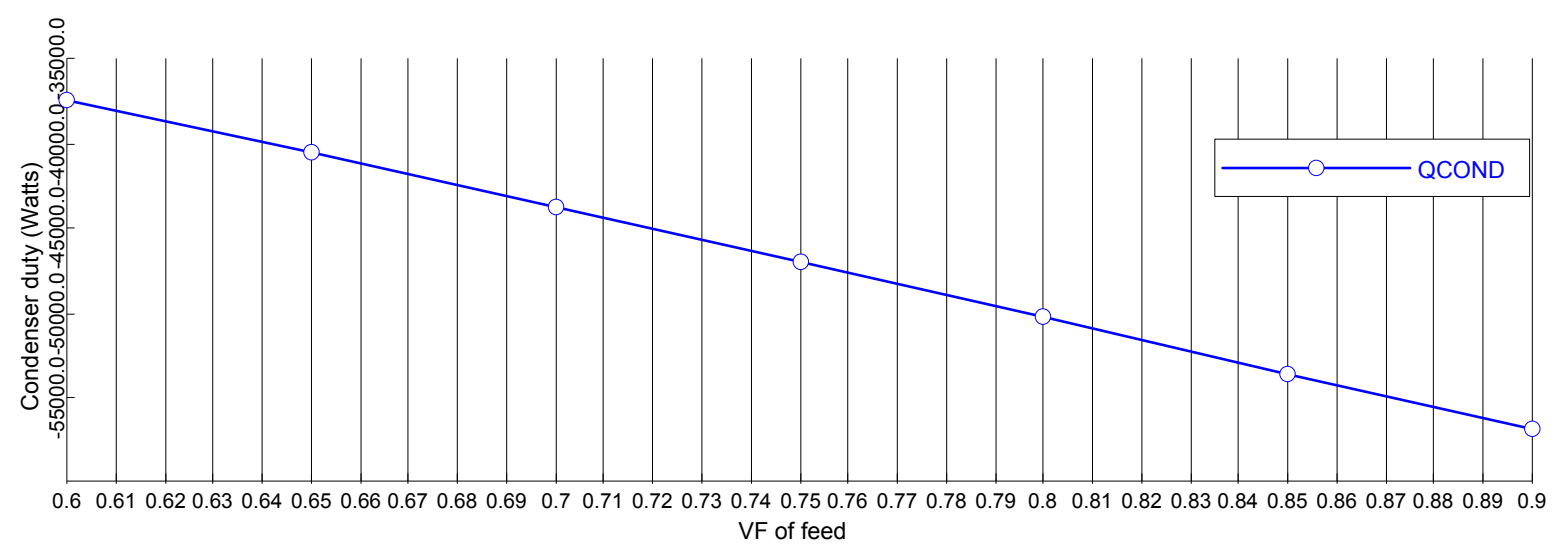

Figure 5. Effect of VF on condenser duty

\subsection{Effect of number of stages on PL Purity and RL (Rich Liquid-Bottoms of HP column) Purity}

In distillation column the vapour flows upward in the column through the liquid, while the liquid flows across the vapour stream towards downwards. At every stage evaporation of $\mathrm{N}_{2}$ and condensation of $\mathrm{O}_{2}$ carried out in counter flow. So as the vapour bubble moves upward through the liquid, it becomes richer in $\mathrm{N}_{2}$ and the liquid through which the bubble moves becomes richer in $\mathrm{O}_{2}$. Thus by using a large number of stages in distillation column PL purity and RL purity are increases as shown in Figure 6 and Figure 7.

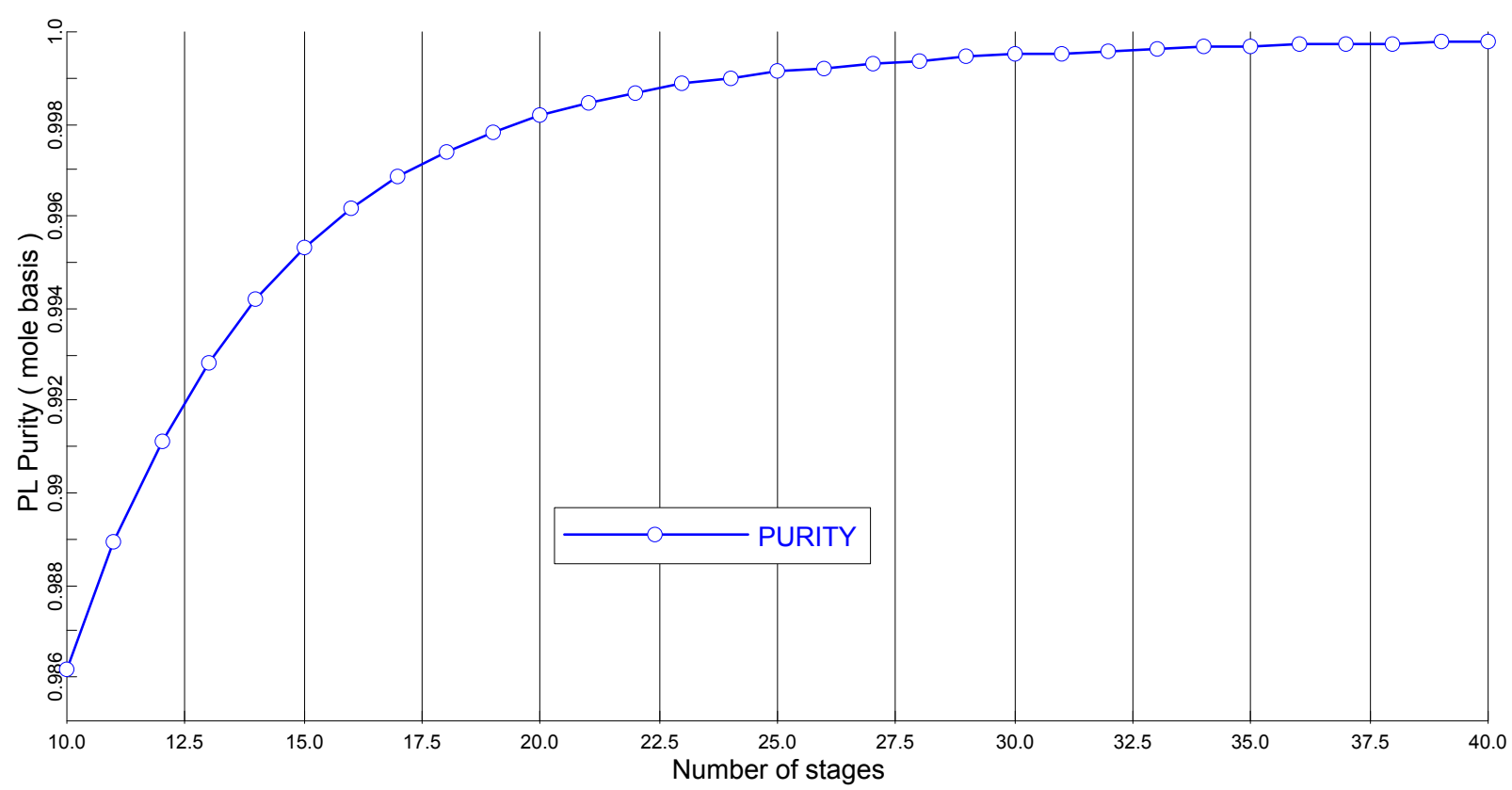

Figure 6. Effect of number of stages on PL purity 


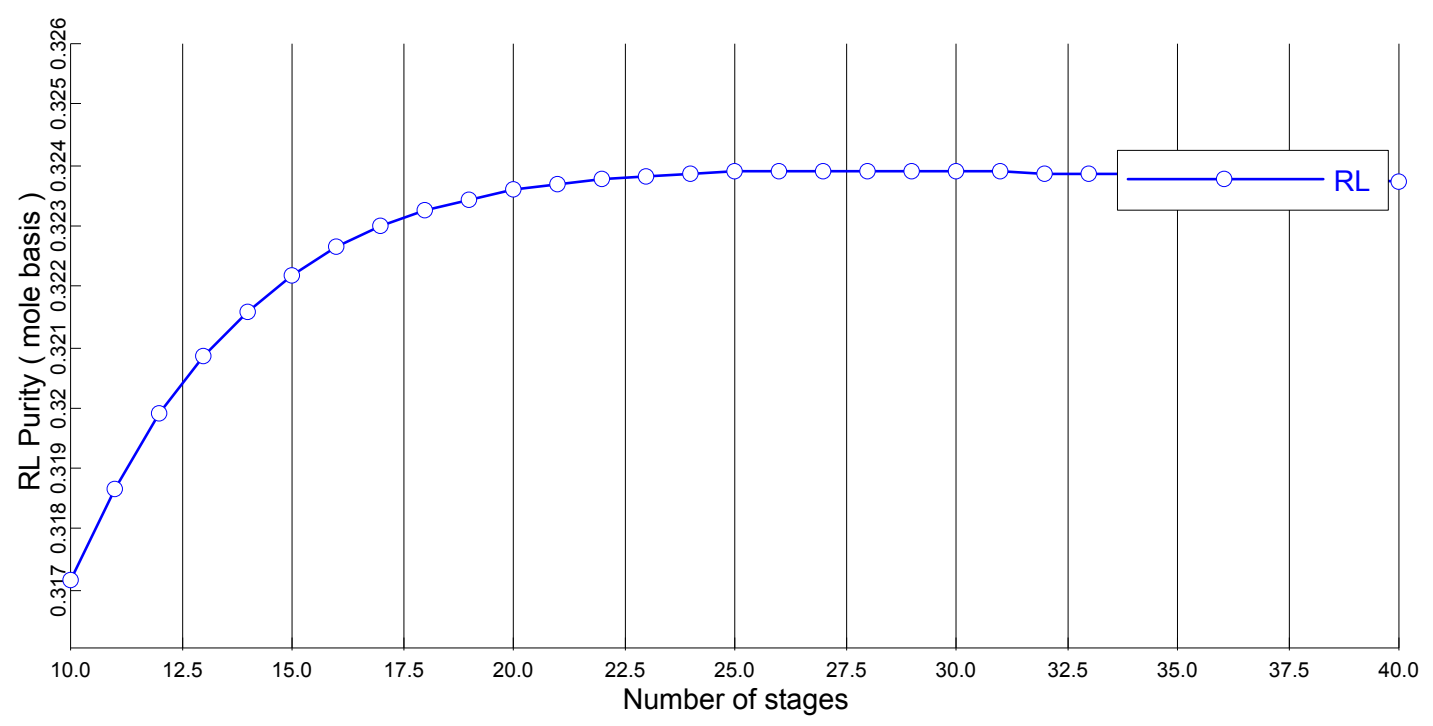

Figure 7. Effect of number of stages on RL purity

\subsection{Effect of VF on PL Purity}

The purity of the top product PL depends on the L/V at the top stage of the HP column. For more VF of the feed air, liquid formation at the top stage will increase due to increased vapour rising to the upper stage. Therefore as VF increases L/V increases which increases the reflux to the HP column for fixed PL flow and PL purity increases as shown in Figure 8.

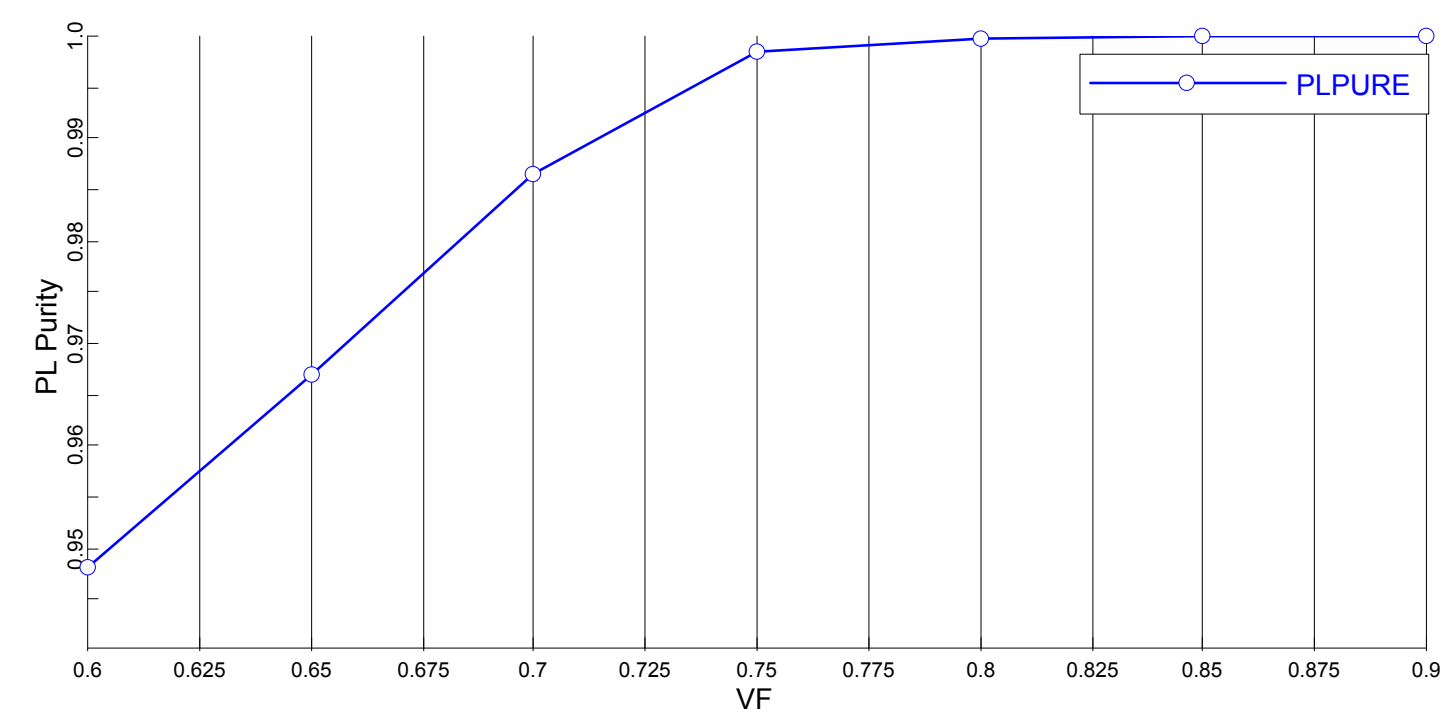

Figure 8. Effect of number of stages on PL purity

\subsection{Effect of Gasification Temperature on Syngas Composition}

It is found that as temperature of gasifier increases $\mathrm{CO}$ and $\mathrm{H}_{2}$ in syngas composition increases while $\mathrm{CO}_{2}$ and $\mathrm{CH}_{4}$ in syngas composition decreases as shown in Figure 9. It is because at high temperature methane decomposes into hydrogen and monoxide carbon as well as shift reaction equilibrium inclines in the production of $\mathrm{CO}$ and $\mathrm{H}_{2} \mathrm{O}$. 


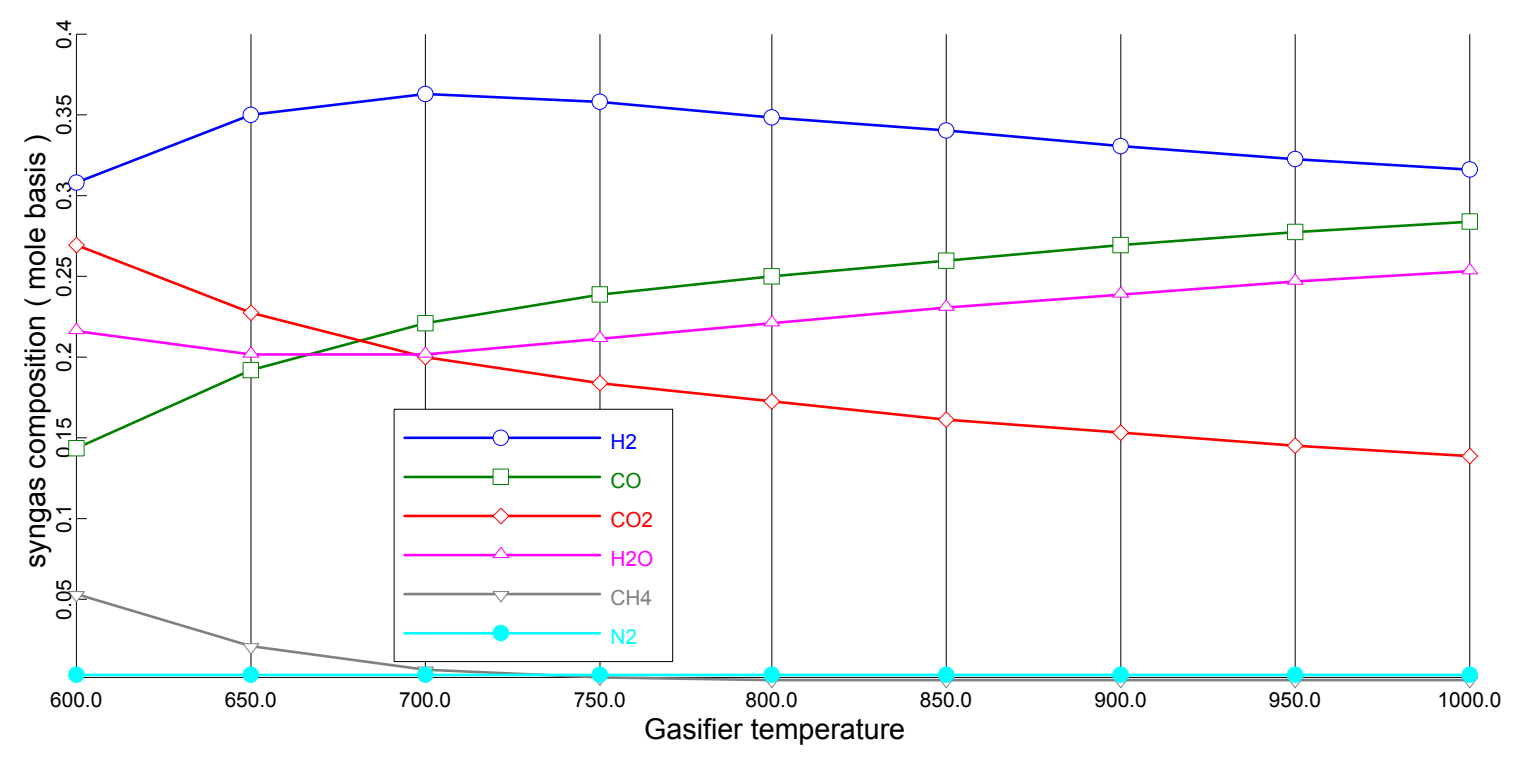

Figure 9. Effect of Gasifier temperature on syngas composition

\subsection{Effect of Oxygen Flow Rate on Syngas Composition}

In gasification process, the air/fuel ratio controls the gasification temperature. The composition profile of individual species in syngas with oxygen flow rate is shown in Figure 10. As oxygen flow rate increases $\mathrm{H}_{2}$ increases and reach maximum at $9 \mathrm{~kg} / \mathrm{hr}$ and then decreases. Similarly as oxygen flow rate increases $\mathrm{CO}$ increases and reach maximum at $12 \mathrm{~kg} / \mathrm{hr}$ and then decreases. As oxygen flow rate increases $\mathrm{CO}_{2}$ decreases reach minimum and then increases. In a similar way $\mathrm{H}_{2} \mathrm{O}$ decreases reach minimum and then increases.

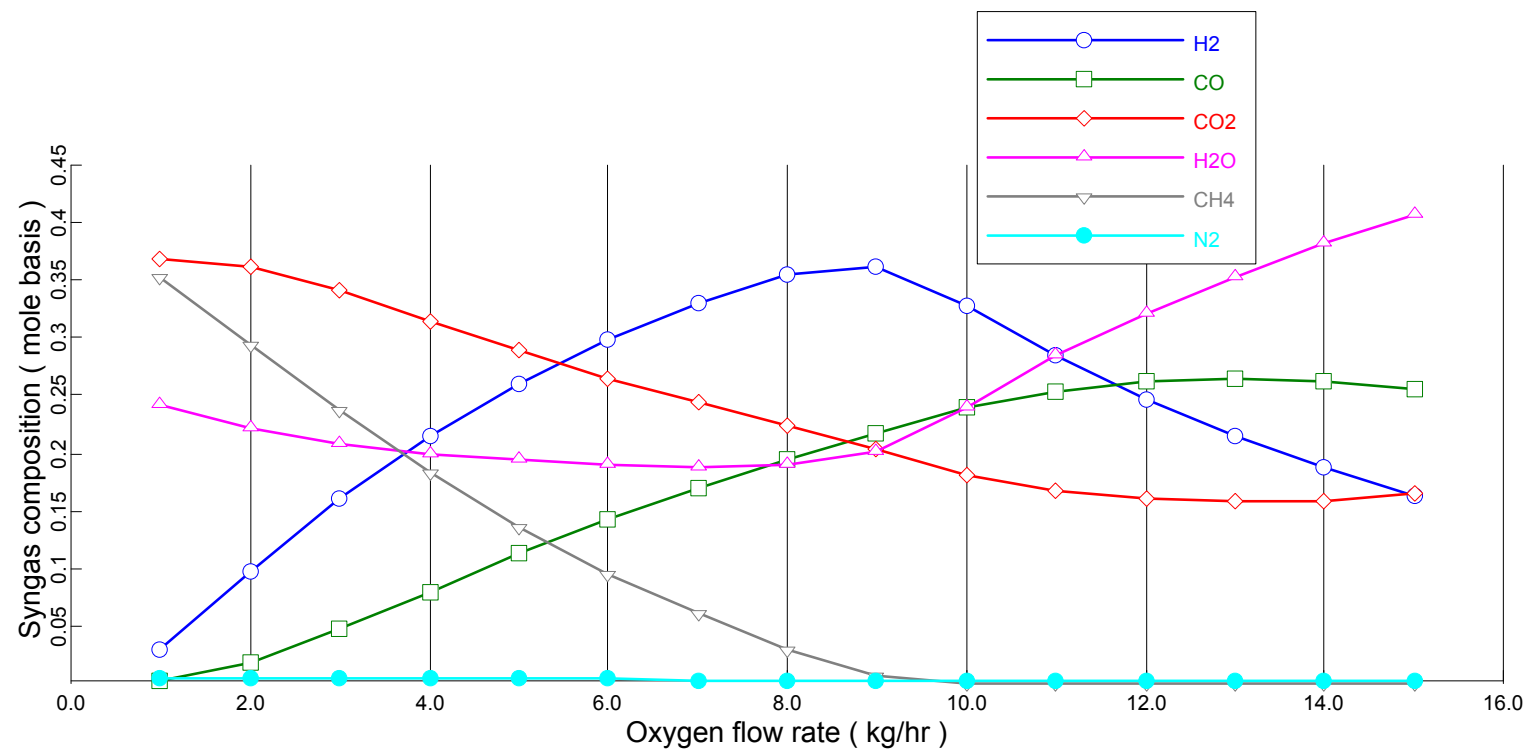

Figure 10. Effect of oxygen flow rate on syngas composition

\section{Conclusion}

The simulation model of cryogenic ASU in Aspen plus predicts production of oxygen with required purity and recovery. Oxygen is obtained with purity $96.2 \%$ which is economically suitable for biomass/coal gasification for getting syngas with a higher heating value. The specific power consumption of the plant obtained is 0.2435 $\mathrm{kw} / \mathrm{scmh}$ of $\mathrm{O}_{2}$, which is lower as compared to conventional cryogenic air separation plants.

It is seen that air gasification produces a syngas with lower heating value, while $\mathrm{O}_{2}$ and steam blown processes 
result in a syngas with a higher heating value. However, the use of oxygen does have other advantages such as operation at lower equivalence ratio, smaller equipment size of gasifier and downstream equipment, and possibly savings in compression cost of produced gas. The parametric analysis of cryogenic ASU integrated with biomass gasifier discussed. It illustrates the impact of various parameters on the desired output of cryogenic ASU integrated with biomass gasifier.

\section{Acknowledgements}

The authors are grateful to Dr. L.G. Navale, Principal and Prof. A.J. Hake, Vice Principal, MES College of Engineering, Pune for their active help and guidance. We are also thankful to Dr. Uday Kulkarni for giving guidelines in the simulation of Cryogenic air separation plant.

\section{References}

Agrawal, R., Erickson, D. C., \& Woodward, D. W. (1989). High efficiency processes for cryogenic air separation. Air products and chemicals, 33-36.

Anil, Khadse, Prasad, Parulekar, Preeti, Aghalayam, \& Anuradda, Ganesh. (2006). Equilibrium model for biomass gasification. Advances in Energy Research, IIT Mumbai.

Aspen plus 11.1 (2011). User Manual guide, Aspen Technology.

Castle, W. F. (2000). Air separation and liquefaction: recent developments and prospects for the beginning of the new millennium. International Journal of Refrigeration, 25(1), 158-172 http://dx.doi.org/10.1016/S0140-7007(01)00003-2

Chawdhury, M. A., \& Mahkamov, K. (2011). Development of small downdraft biomass gasifier for developing countries. Journal of Scientific Research, 3(1), 51-64. http://dx.doi.org /10.3329/jsr.v3i1.5613

Chen, Po-Chuang, Chiu, Hsiu-Mei, Chyou, Yau-Pin, \& Yu, Chiou-Shia. (2010). Processes simulation study of coal to methanol based on gasification technology. World academy of science, engineering and technology, 65.

Mandler, Jorge A. (2000). Modeling for control analysis and designing complex industrial separation and liquefaction process, Journal of process control, 10(2-3), 167-175. http://dx.doi.org/10.1016/S0959-1524(99)00021-9

Mansaray, K. G., Ghaly, A. E., Al-Taweel, A. M., Ugursal, V. I., \& Hamdullahpur, F. (2010). Mathematical modeling of a fluidized bed rice husk gasifier: Part III - Model verification. Energy sources Part A: Recovery, utilization and Environmental effects, 22(3), 281-296. http://dx.doi.org/10.1080/00908310050014063

Paviet, Chazarency, \& Tazeroutz. (2009). Thermo chemical equilibrium modelling of a biomass gasifying process usng ASPEN PLUS. International Journal of chemical reactor engineering, 7(1), 1542-6580. http://dx.doi.org/10.2202/1542-6580.2089

Sapali, S. N. (2001). A Thesis on cryogenic air separation plants: Parametric evaluation and exergy analysis. Ph.D.Thesis, IIT Kharagpur.

Schuftan, P. M. (1948). Modern gaseous oxygen production methods. Transactions Institute of chemical Engineers, 26a, 30-37.

Shrinivas, A. V. S., Gupta, S. K. S., \& Reddy, B. V. (2009). Thermodynamic equilibrium model and exergy analysis of biomass gasifier. Journal of energy resources technology, ASME, 131(3), 1-7. http://dx.doi.org/10.1115/1.3185354

Smith, A. R, \& Klosek, J. (2001). A review of air separation technologies and their integration with energy conversion processes. Fuel processing technology, 2(2), 115-134. http://dx.doi.org/10.1016/S0378-3820(01)00131-X

Wayne, Doherty, Anthony, Reynolds, \& David, Kennedy. (2008). Simulation of a circulating fluidised bed biomass gasifier using ASPEN plus: a performance analysis. International conference on efficiency, cost, optimiztion, simulation and environmental impact of energy systems Karkow, poland, 1241-1248.

Zhu, Y., Liu, X. G., \& Zhou, Z. Y. (2006). Optimization of cryogenic air separation distillation columns. Proceeding of the world congress on intelligent control and automation, 7702-7705.

Zhu, Yu, Legg, Sean, \& Laird Carl, D. (2010). Optimal design of cryogenic air separation columns under uncertainty. Computers and chemical Engineering, 34(9), 1377-1384. http://dx.doi.org/10.1016/j.compchemeng.2010.02.007 